\title{
Antero-posterior mandibular position at different vertical levels for mandibular advancing device design
}

\author{
P. Mayoral' ${ }^{1}$ M. O. Lagravère ${ }^{2 *}$, M. Míguez-Contreras ${ }^{3}$ and M. Garcia ${ }^{4}$
}

\begin{abstract}
Introduction: Mandibular Advancement Devices (MAD) have been reported to be an alternative treatment to CPAP in moderate to severe obstructive sleep apnea (OSA) cases. The design of MAD has a major influence on its success rate on the patient, and design features that have an influence on efficacy, tolerance, and compliance. The aim of this study was to determine the range of mandibular protrusion at different vertical points; 2, 5, 8 and $11 \mathrm{~mm}$ in a young adult population.

Methods: Fifty two students aged 19 to 23 years (mean 21.3 $1.7 ; 29$ females and 23 males), with full permanent dentition participated in the study. The absolute range of maximal mandibular protrusion and retrusion was measured $(\mathrm{mm})$ with the use of the George Gauge. Descriptive statistics, ANOVA and paired t-test using SPSS were used.

Results: Range of mandibular advancement was possible to be determined for the 4 levels of vertical opening with the gauges: $2 \mathrm{~mm}$ fork mean mandibular advance $13,10 \mathrm{~mm} \pm 0.604 ; 5 \mathrm{~mm}$ mean $11.98 \mathrm{~mm} \pm 1.075 ; 8 \mathrm{~mm}$ mean 11.20 $\mathrm{mm} \pm 1.369 ; 11 \mathrm{~mm}$ mean $9.87 \mathrm{~mm} \pm 1.886$. No significant differences were found between class I, II, and III.

Conclusions: There is an impact of increased inter-incisal distance of effective mandibular protrusion when constructing a MAD. As vertical dimension increases the mandible rotates posteriorly and places itself in a more retrusive location, and the range of mandibular advancement reduces $(0.3 \mathrm{~mm}$ for every $1 \mathrm{~mm}$ of vertical increase).
\end{abstract}

Keywords: Obstructive sleep apnea. Mandibular advancement device. Oral appliance design. Mandibular position, Vertical opening. Mandibular protrusion

\section{Introduction}

One of the symptoms of Obstructive sleep apnea (OSA) is the presence of recurrent episodes of partial/complete collapse of the upper airway [1]. This may lead to a fragmentation of the sleep pattern, a decrease in oxygen saturation and a partial pressure rise of $\mathrm{CO}_{2}$ in the blood [2]. The arousals and the nocturnal hypoxemia can cause excessive daytime sleepiness, loss of concentration, hypertension and atherosclerosis [3]. In more severe cases, OSA may lead to stroke and heart failure, resulting in an increased prevalence of cardiovascular morbidity and mortality [4].

\footnotetext{
* Correspondence: mlagravere@ualberta.ca

¿University of Alberta, Faculty of Medicine and Dentistry, School of Dentistry, ECHA 5-524, 11405-87 Avenue, Edmonton, Alberta T6G 1C9, Canada

Full list of author information is available at the end of the article
}

A type of treatment for OSA consists of the use of mandibular advancement devices (MAD) $[1,5]$. These appliances keep the mandible in a forward/protruded position during sleep increasing the width of the airway and reducing its collapsibility [6]. Even though there are conflicting reports on the success rate of these appliances [1] [7], MAD have been reported to be an alternative treatment to Continuous Positive Airway Pressure (CPAP) in moderate to severe OSA cases $[6,8]$.

It should be noted that the range of success of MAD is limited and can present a high variability between individuals [9]. Clinical evidence over the success rate of MAD are not conclusive thus more research is needed to be able to determine its predictability $[10,11]$.

The design of the MAD has a major influence on its success rate on the patient [12], and the design features

(c) The Author(s). 2019 Open Access This article is distributed under the terms of the Creative Commons Attribution 4.0 International License (http://creativecommons.org/licenses/by/4.0/), which permits unrestricted use, distribution, and 
have an influence on efficacy, tolerance, and compliance $[13,14]$.

There are two important aspects involved in making MAD which are the amount of vertical opening and the degree of mandibular protrusion. In general terms, the more advancement of the mandible, the better treatment results which should be balanced with the potential appearance increase of side effects [1].

Protrusion has been reported to happen by the body translation of the condyles [15]. During protrusion, the condyle translates following the contour of the articular eminence being affected by the steepness of the posterior slope of it [15]. Increasing the vertical dimension causes posterior rotation of the mandible with two adverse effects: possible reduction of maximum protrusive capacity and an increased posterior position of the mandible.

The use of incorrectly designed MAD which give an inappropriate level of protrusion for example short protrusion will not produce an effective reduction of the Apnea Hiponea Index (AHI) [16] and minimal change in total pharyngeal area [17]. If the MAD cause a long protrusion in the patients, it can cause temporomandibular joint issues and negative occlusal changes [18] which limit the effectiveness of the appliance and treatment overall. It is worth noting that an increased vertical mouth opening has an adverse effect on upper airway patency in the majority of OSA patients [19].

The purpose of the study was to determine the impact of increased vertical dimension on the range of protrusion of the mandible. Few authors have studied the range of protrusive movements $[20,21]$, but none at different vertical levels. Since MAD are constructed at various vertical levels, the aim was to determine the range of mandibular protrusion at different vertical points; 2 , 5,8 and $11 \mathrm{~mm}$ in a young adult population. This information will help in determining a guide for construction and application of a MAD appliance.

\section{Methods}

Fifty-two students of Dentistry at the Universidad Alfonso X Madrid, aged 19 to 23 years (mean age 21.3 SD 1.7; 29 females and 23 males) agreed to participate in this study. All subjects were asymptomatic for temporomandibular disorders, according to the Research Diagnostic Criteria/ Temporomandibular Disorders RDC/ TMD, RDC /TMD [13]. This study was approved by the ethical review board of Universidad Alfonso X Madrid UAX 2016-021 and written consent was obtained from all participants. All patients had full permanent dentition up to the second molar. None had previous maxillofacial surgery nor TMJ symptomology.

Each subject had a lateral cephalometric radiograph done at the start of the study with profile and frontal extraoral photos. Lateral cephalograms were landmarked using the Kinovea software (Kinovea, France). X and $\mathrm{Y}$ coordinates were determined for each landmark. Distances and angles were measured and placed in an excel worksheet. Table 1 lists the landmarks with respective definitions used. Table 2 lists distances and angles measured on each radiograph.

When taking measurements after doing the different vertical openings, patients were asked to sit straight in the dental chair. The absolute range of maximal mandibular protrusion and retrusion was measured (in $\mathrm{mm}$ ) with the use of the George Gauge (Great Lakes Orthodontics, Ltd., New York, USA) [22] (Fig. 1). Then, the principal investigator took measurements of the maximum protrusion range with 4 different George Gauge bite forks $(2 \mathrm{~mm}, 5$ $\mathrm{mm}, 8 \mathrm{~mm}$, and $11 \mathrm{~mm}$ of interincisal vertical opening) (Table 3). By definition, maximum retrusion was considered when the lower incisors were located behind the upper incisors (negative value) and maximum protrusion was considered when the lower incisors were located in front of the upper incisors (positive value) (Fig. 2).

Maximun retrussion was also calculated using the cephalometric radiograph. As Posselt mentions [23] the posterior curve represents the motion limit of the mandible in its most posterior location. This occurs as a rotational movement of the mandible in its hinge in the center of the condyles [24]. This movement is represented as an arch with its center in the condyle (landmark $\mathrm{Co}$ ) and having the curve pass through the inferior incisor through the line connecting the condyle and inferior incisor (Co-II) (Fig. 3).

Once the posterior curve was determined, discontinuous curve in Fig. 4, the maxillary occlusal plane was defined as the movement plane of the mandible using the Gauge. This was to compare the measurements obtained from the Gauge to the ones from the radiograph. Lastly, parallel lines to the maxillary occlusal plane were drawn representing Gauges 2,5,8 and 11 of opening. Then the

Table 1 Cephalometric landmarks used in the study

\begin{tabular}{ll}
\hline Landmark & Definition \\
\hline A-point (A) & $\begin{array}{l}\text { Deepest point of the maxillary base between the } \\
\text { anterior nasal spine and the alveolar crest } \\
\text { B-Point (B) }\end{array}$ \\
$\begin{array}{l}\text { Deepest point in the concavity of the anterior } \\
\text { border of the symphysis }\end{array}$ \\
Condyle (Co) & $\begin{array}{l}\text { Mesiobuccal cusp of the upper first molar } \\
\text { Incisor superior (IS) }\end{array}$ \\
Incisor inferior (II) & $\begin{array}{l}\text { The most inferior anterior point of the incisal } \\
\text { edge of the maxillary incisor } \\
\text { edge of the mandibular incisor }\end{array}$ \\
Nasion (N) & $\begin{array}{l}\text { Most anterior superior point at the intersection } \\
\text { of the nasal bone and the nasofrontal suture } \\
\text { in the midsagittal plane } \\
\text { Center of sella turcica }\end{array}$ \\
\hline
\end{tabular}


Table 2 Measurements of the study

\begin{tabular}{|c|c|}
\hline Measurement & Definition \\
\hline \multicolumn{2}{|l|}{ Angles } \\
\hline SNA & Angle formed by the planes S-N and N-A \\
\hline SNB & Angle formed by the planes S-N and N-B \\
\hline ANB & Angle formed by the planes N-A and N-B \\
\hline \multicolumn{2}{|c|}{ Especial Measurements } \\
\hline galgarx2 & $\begin{array}{l}\text { Distance from tip of upper incisor (landmark IS), } \\
\text { parallel to the occlusal plane at } 2 \mathrm{~mm} \text {, to arch } \\
\text { with its center in the condyle (landmark Co) } \\
\text { and having the curve pass through the inferior } \\
\text { incisor (landmark II) }\end{array}$ \\
\hline galgarx5 & Same as before at $5 \mathrm{~mm}$ \\
\hline galgarx8 & Same as before at $8 \mathrm{~mm}$ \\
\hline galgarx11 & Same as before at $11 \mathrm{~mm}$ \\
\hline
\end{tabular}

distance was measured between the incisor position and the theoretic posterior curve as seen in Fig. 4.

Distances were calculated using the coordinates obtained from each landmark using the Euclidean distance. Samples were also categorized into skeletal relationship Class I, II or III based on their ANB measurement obtained from the cephalometric radiographs. (ANB: Class III <1degree, Class I $>1$ and $<5$, Class II $>5$. Table 3 shows the distribution of the sample with respect to Class, age and gender.

Ten radiographs were randomly selected and landmarked three times leaving one week in between trials to calculate reliability of the measurements. Interclass Correlation Coefficient was used to calculate the reliability as well as the measurement error for each landmark in each coordinate. Descriptive statistics were used as well as ANOVA and paired t-test using SPSS (version 24, IBM, New York, USA).

\section{Results}

All landmarks presented excellent reliability values with the lowest landmark being 0.97 (CI 95\% 0.94;0.99) in the A point $y$-axis. The majority of landmarks had an average of $>1 \mathrm{~mm}$ error in all coordinates.

Once reliability was determined, all cephalograms were landmarked and measured. Range of mandibular
Table 3 Total mandibular advance in milimeters

\begin{tabular}{|c|c|}
\hline Landmark & Definition \\
\hline A-point (A) & $\begin{array}{l}\text { Deepest point of the maxillary base between } \\
\text { the anterior nasal spine and the alveolar crest }\end{array}$ \\
\hline B-Point (B) & $\begin{array}{l}\text { Deepest point in the concavity of the anterior } \\
\text { border of the symphysis }\end{array}$ \\
\hline $6 s$ & Mesiobuccal cusp of the upper first molar \\
\hline Condyle (Co) & The center point of the condyle \\
\hline Incisor superior (IS) & $\begin{array}{l}\text { The most inferior anterior point of the incisal } \\
\text { edge of the maxillary incisor }\end{array}$ \\
\hline Incisor inferior (II) & $\begin{array}{l}\text { The most superior anterior point of the incisal } \\
\text { edge of the mandibular incisor }\end{array}$ \\
\hline Nasion (N) & $\begin{array}{l}\text { Most anterior superior point at the intersection } \\
\text { of the nasal bone and the nasofrontal suture in } \\
\text { the midsagittal plane }\end{array}$ \\
\hline Sella (S) & Center of sella turcica \\
\hline
\end{tabular}

advancement was determined for the 4 levels of vertical opening with the gauges (Fig. 5). It was found that as the vertical opening increased, the range of anteroposterior movement of the mandible decreased. (Table 3) Patient were diagnosed using skeletal relationships obtained from the radiographs to group them into Class I, II or III. No significant differences were found between class I, II, and III, although patients classified as Class III had a larger range of motion compared to Class II patients.

Figure 2 illustrates that as the vertical dimensions increased to $8 \mathrm{~mm}$, the mandibular position became more retrusive, but when it is increased to $11 \mathrm{~mm}$, the retrusion diminished.

When viewing the values obtained by the Gauge from the Gauge of George and the values from the radiographs, it was found that both presented a positive correlation. The higher the gauge, the greater the value obtained as seen in Table 4.

\section{Discussion}

To our knowledge, this is the first study in which the maximum protrusive capacity of an adult population

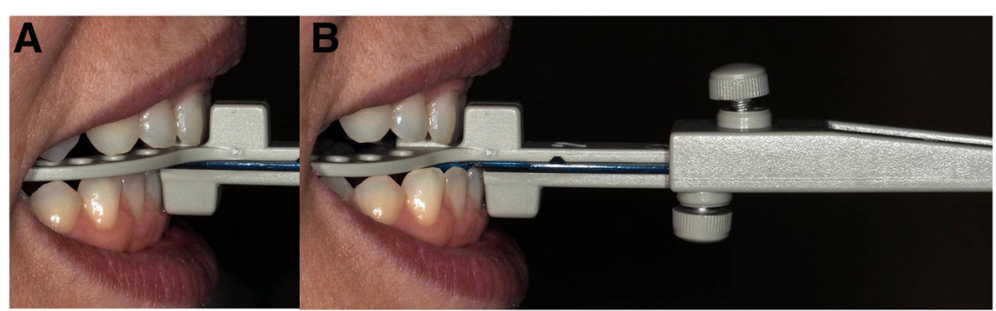

Fig. 1 George gauge maximum retrusion and maximum protrusion. Shows how the absolute range of maximal mandibular retrusion (a) and protrusion (b) was measured (in $\mathrm{mm}$ ) with the use of the George Gauge. 


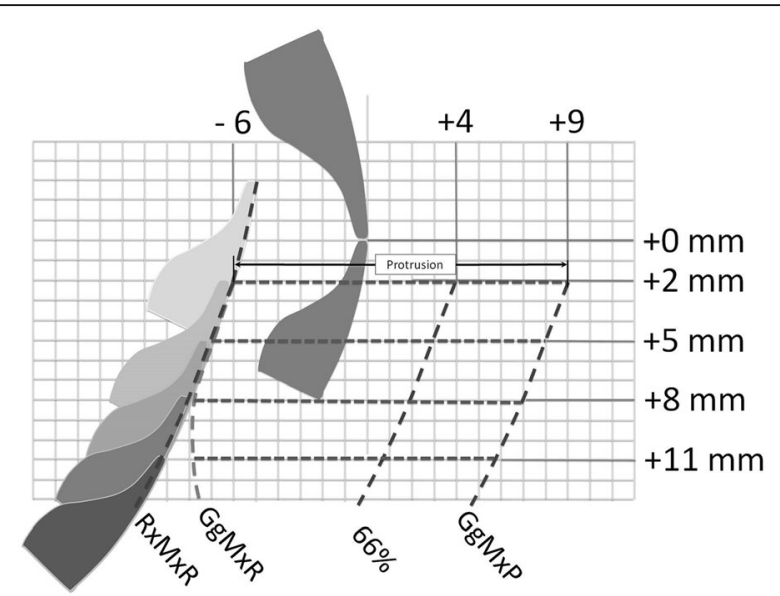

Fig. 2 Position of lower incisor in relation to upper incisor. RxMxR shows the maximum retrusion calculated with the radiograph. GgMxR shows the maximum retrusion obtained with the George Gauge. $66 \%$ shows the position of the lower incisor with $66 \%$ of maximum protrusion. GgMxP shows the maximum protrusion obtained with the George Gauge. Values obtained with the George Gauge with $2 \mathrm{~mm}$ of vertical opening are shown on the figure; -6 $\mathrm{mm}$ for maximum retrusion; $+9 \mathrm{~mm}$ for maximum protrusion, +4 for $66 \%$ of total advance.

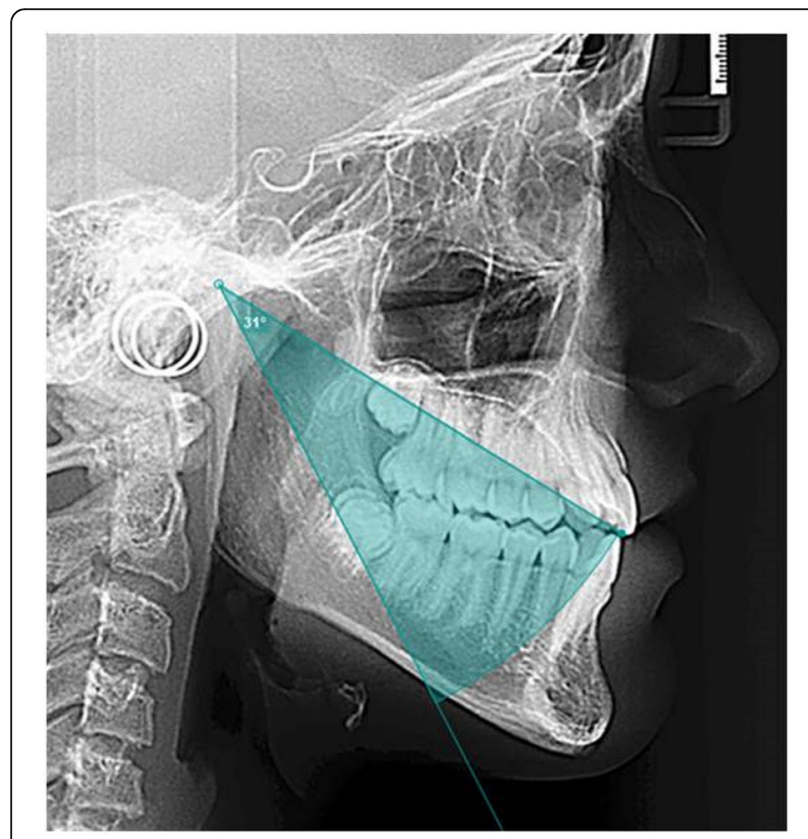

Fig. 3 Rotational movement of the mandible. Shows how the rotational movement of the mandible was calculated in each patient with the cephalometric radiography. The rotational movement is an arch with its center in the condyle (landmark Co) and having the curve pass through the inferior incisor through the line connecting the condyle and inferior incisor (Co-II).

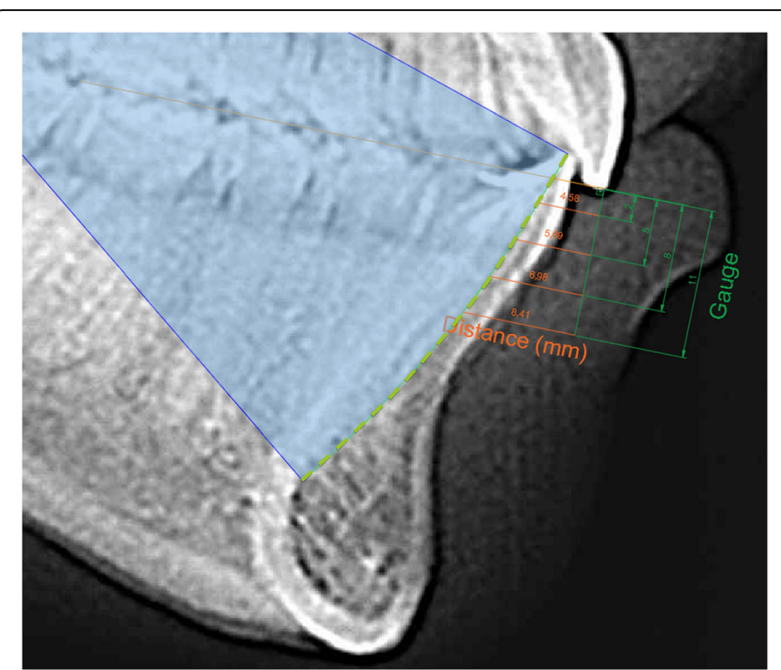

Fig. 4 Planes at different vertical opening levels. Shows the curve of the rotational movement, discontinuous curve, the maxillary occlusal plane used with the Gauge, and the parallel lines to the maxillary occlusal plane representing Gauges 2,5,8 and $11 \mathrm{~mm}$ of opening.

was measured with George Gauge with four levels of vertical increase. Two factors that can affect the mandibular advancement and the efficiency of the MAD have been studied. With an increase in the vertical dimension, the range of mandibular advancement reduces $(0.3 \mathrm{~mm}$ for every $1 \mathrm{~mm}$ of vertical increase up to $8 \mathrm{~mm}$ of interincisal distance). Also, with an increase in the vertical dimension, the mandible rotates posteriorly and places itself in a more retrusive location. To compensate for this vertical increase, it is necessary to increase the amount of mandibular advancement when constructing the MAD (Fig. 2). The rationale for the present study was to determine the range of advancement at four different vertical levels in a young adult population. As a result from this, it was found that the range of advancement also produces posterorotation.

It is important to identify the maximum protrusion in a young adult since this serves as a reference for the maximum protrusion that can be accomplished using MAD. The MAD are made so that mandibular advancement can occur that will open and keep the airway open when the patient is sleeping. Knowing the values of normal range will make it possible to design an appliance that will be effective, tolerated by the patient and will not produce secondary effects.

Few studies have registered maximum protrusions of the mandible and no study was found that correlated it with an increase in the vertical dimension. Children present a protrusion from 5 to $6 \mathrm{~mm}$ [25]. Bonjardim et al. [25] analyzed this in children 3-5 years of age and found that the maximum protrusion was $5.67 \mathrm{~mm} \pm$ $1.76 \mathrm{~mm}$ in Class I groups and $6.12 \mathrm{~mm} \pm 1.92 \mathrm{~mm}$ in Class II groups. Adolescents have a protrusion of 10.6 


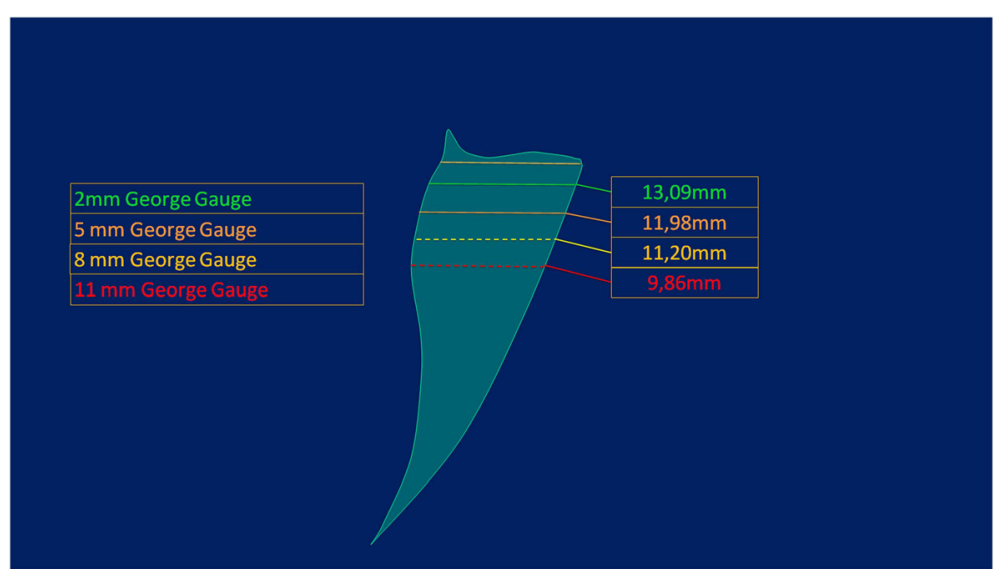

Fig. 5 Normal range of maximum protrusion at different vertical opening levels. Shows the range of maximum protrusion obtained in our study for the different vertical opening levels and with it, constructed the Posselt diagram of border movements of the mandible.

$\mathrm{mm} \pm 3.2[26]$. These values are smaller than the ones found in the present study although the present study analyzed older patients.

Adults present a mandibular protrusion on average of 9-11 $\mathrm{mm}$ [27-31] with a sample range of variation (5-16 $\mathrm{mm}$ ) between individuals [28] [30] which are smaller values compared to the present study. Ingervall's study [28] found in an adult female sample ( 21 years old) that the maximum distance was $9 \mathrm{~mm}$ (range 5 to14mm). Posselt [27] found values of $11 \mathrm{~mm}$ (10 to $14 \mathrm{~mm}$ ) in both females and males. Agerberg [29] also found values of 10 $\mathrm{mm}$ for both genders between 18 and 25 years of age.

When designing a MAD, different degrees of mandibular protrusion and vertical opening should be considered but the decision of what is optimal is still questionable. [8, 32, 33].

Protrusion positions with $25,33,50,67,75$, and $100 \%$ of the maximum mandibular protrusion have been examined in previous studies [34-46]. The degree of advancement is usually expressed as a \% of maximum protrusive capacity or/and in millimeters $(\mathrm{mm})$. Percentage of maximum protrusive capacity is used in reference to potential side effects and percentage or millimeters to effectiveness in opening the upper airway.

Mandibular protrussion effects has been researched more than the effect of vertical openings [8, 17, 32, 33]. With that being considered, the more appropriate vertical opening in terms of treatment is still debatable $[8,17,33]$.

Table 4 Maximum retrusion on Radiograph vs George Gauge

\begin{tabular}{|c|c|c|c|c|c|c|}
\hline & Vertical opening & $\mathrm{N}$ & Min & Max & Mean & SD \\
\hline \multirow[t]{4}{*}{ Radiograph } & $2 \mathrm{~mm}$ & 52 & $-9,28$ & $-1,54$ & -4.87 & 1.557 \\
\hline & $5 \mathrm{~mm}$ & 52 & $-10,63$ & $-2,96$ & -6.07 & 1.570 \\
\hline & $8 \mathrm{~mm}$ & 52 & $-12,09$ & $-4,23$ & -7.36 & 1.610 \\
\hline & $11 \mathrm{~mm}$ & 52 & $-13,66$ & $-5,64$ & -8.76 & 1.667 \\
\hline \multirow[t]{6}{*}{ George Gauge } & $2 \mathrm{~mm}$ & 47 & $-8,50$ & $-3,00$ & -5.48 & 1.339 \\
\hline & $5 \mathrm{~mm}$ & 52 & $-9,00$ & $-3,00$ & -5.45 & 1.311 \\
\hline & $8 \mathrm{~mm}$ & 52 & $-9,00$ & $-3,00$ & -6.27 & 1.293 \\
\hline & $11 \mathrm{~mm}$ & 52 & $-10,00$ & $-3,00$ & -6.10 & 1.704 \\
\hline & & \multicolumn{2}{|c|}{ Paired Samples Correlations } & \multicolumn{2}{|c|}{ Paired Differences } & \\
\hline & & Correlation & Sig. & Mean & SD & Sig. (2-tailed) \\
\hline \multirow[t]{4}{*}{ Radiograph \& George Gauge } & $2 \mathrm{~mm}$ & 0.603 & 0.000 & 1.26465 & 0.18447 & 0.026 \\
\hline & $5 \mathrm{~mm}$ & 0.565 & 0.000 & 1.35309 & 0.18586 & 0.003 \\
\hline & $8 \mathrm{~mm}$ & 0.490 & 0.000 & 1.51619 & 0.21231 & 0.000 \\
\hline & $11 \mathrm{~mm}$ & 0.349 & 0.011 & 1.99586 & 0.27678 & 0.000 \\
\hline
\end{tabular}

$N$ Number of patients

SD Standard Deviation

5 patients had overbite of less than $2 \mathrm{~mm}$ which didn't allow to use the fork of $2 \mathrm{~m}$ 
Some degree of vertical opening is unavoidable because of device design features and an appropriate degree of vertical opening is desirable for optimizing the forward displacement of the mandible [47]. The amount of vertical opening used in different devices is given in millimeters (range 1-14 mm) [8, 34, 38-40, 42-44]. Although studies have shown that appliances with both an increased [38, $48,49]$ or minimal $[49,50]$ vertical dimension are effective, physiologic evidence suggest that the vertical dimension should be kept to a minimum to optimize treatment outcome [24]. Our results help to understand the findings of Piskin where the most increase happened in the pharynx with a splint having the least vertical occlusion with the highest degree of protrussion [17]. Furthermore, an increased vertical mouth opening has an adverse effect on upper airway patency in the majority of OSA patients [19]. For this reason, the amount of bite opening should be minimized which improves patient tolerance and positive effect on upper airway [1].

In the present study, similar to the Piskin study, the inclusion of full permanent dentition patients with unaffected vertical occlusion was to confirm that the vertical opening was functional and not because of loss of teeth [17].

No significant differences were found between patients skeletal class I, II, and III for the range of anteroposterior movement of the mandible (Table 3 ) for $2 \mathrm{~mm}$ interincisal vertical opening. Although patients classified as Class III had a greater range of motion compared to Class II patients for 5, 8 and $11 \mathrm{~mm}$. Patients with skeletal Class II have shorter or more retrusive mandibles than Class III, and this makes Class II subjects to have a more retrusive path of aperture which could explain the smaller range of anteroposterior movement.

When viewing the values of maximum retrusion obtained from the Gauge of George and the values from the radiograph, it was found that both presented a positive correlation for 2, 5 and $8 \mathrm{~mm}$ but not for $11 \mathrm{~mm}$ (Table 4). When analyzing the data, it was found that as the vertical dimensions increased from 2 to $8 \mathrm{~mm}$, the mandibular position becomes more retrusive. However, when it increased to $11 \mathrm{~mm}$, the retrusion diminishes as observed in Fig. 2. This suggests that the point where pure rotation ends and rotation plus translation starts is about $8 \mathrm{~mm}$ of interincisal distance and this is consistent with previous studies [24] that stated that the translation and rotation occurred simultaneously from early opening.

Mandibular movement presents a difficult pattern to describe [51], however, the results of our study can partially be explained by the concept of the functionality of mandibular movement and therefore necessary to consider when making a MAD.

The four main areas of variability among MAD are freedom of mandibular movement, amount and rigidity of dental coverage, amount of mandibular advancement and amount of bite opening. Before selecting the parameters of the construction bite, the dentist must carefully weigh the advantages and disadvantages of each millimeter of mandibular forward translation and each degree of downward rotation [12].

One limitation found in the present study is that control for ethnicity was not achievable since the multiethnic backgrounds of the patients made it hard to focus on one specific group. For future studies, comparisons between ethnic groups would be interesting since the overall size of the mandible may play an important role.

Following the results from this study, it is suggested to limit the aperture since each $\mathrm{mm}$ of opening creates a posterior rotation limiting the protrussion.

\section{Conclusion}

There is an impact of increased inter-incisal distance of effective mandibular protrusion when constructing a MAD. As vertical dimension increases the mandible rotates posteriorly and places itself in a more retrusive location. With an increase in the vertical dimension, the range of mandibular advancement is reduced $(0.3 \mathrm{~mm}$ for every $1 \mathrm{~mm}$ of vertical increase up to $8 \mathrm{~mm}$ of interincisal distance). It is recommended to limit the amount of opening or increase in the vertical dimension in patients that would use MAD.

Before selecting the parameters of the construction bite, the dentist must carefully weigh the advantages and disadvantages of each millimeter of mandibular forward translation and each degree of downward rotation.

\section{Abbreviations \\ AHI: Apnea Hipopnea Index; CPAP: Continuous Positive Airway Pressure; MAD: Mandibular Advancement Device; OSA: Obstructive Sleep Apnea; RDC: Research Diagnostic Criteria; TMD: Temporomandibular Disorders}

\section{Acknowledgements}

The authors would like to thank Ms. Ana Fernandez for her valuable support.

\section{Funding}

This research did not receive any specific grant from funding agencies in the public, commercial, or not-for-profit sectors.

\section{Availability of data and materials}

The datasets used and/or analyzed during the current study are available from the corresponding author on reasonable request.

\section{Authors' contributions}

All authors have read and approved the final manuscript. PM contributed to the conception and design of the study and analysis/interpretation of the data, was involved in writing the manuscript, and approved the final version to be published. ML contributed to the conception and design of the study and analysis/interpretation of the data, and approved the final version to be published. MM was involved in drafting the manuscript and revising it critically for important intellectual content, and approved the final version to be published. MG contributed to the design of the study and analysis/ interpretation of the data, and approved the final version to be published.

Ethics approval and consent to participate

This study was approved by the ethical review board of Universidad Alfonso X Madrid UAX 2016-021 and written consent was obtained from all participants. 


\section{Consent for publication}

Not applicable.

\section{Competing interests}

The authors declare that they have no competing interest.

\section{Publisher's Note}

Springer Nature remains neutral with regard to jurisdictional claims in published maps and institutional affiliations.

\section{Author details}

'Catholic University of Murcia UCAM, Faculty of Medicine and Dentistry, School of Dentistry and Scientific Committee Orthoapnea, Flauta Mágica 22, 29006 Málaga, Spain. ${ }^{2}$ University of Alberta, Faculty of Medicine and Dentistry, School of Dentistry, ECHA 5-524, 11405-87 Avenue, Edmonton, Alberta T6G 1C9, Canada. ${ }^{3}$ Catholic University of Murcia UCAM, Faculty of Medicine and Dentistry, School of Dentistry, Madrid, Spain. ${ }^{4}$ University of Malaga, Faculty of Engineering and Scientific Committee Orthoapnea, Flauta Mágica 22, 29006 Málaga, Spain.

\section{Received: 22 September 2017 Accepted: 8 May 2019}

\section{Published online: 22 May 2019}

\section{References}

1. Sutherland K, Vanderveken OM, Tsuda H, Marklund M, Gagnadoux F, Kushida CA, Cistulli PA. Oral appliance treatment for obstructive sleep apnea: an update. J Clin Sleep Med. 2014;10(2):215-27.

2. Javaheri S, Barbe F, Campos-Rodriguez F, Dempsey JA, Khayat R, Javaheri S, Martinez-Garcia A, MA MR, AI P, Polotsky VY, Redline S, Somers VK. Sleep apnea. types, mechanisms, and clinical cardiovascular consequences J Am Coll Cardiol. 2017;69(7):841-58

3. Aurora RN, Collop NA, Jacobowitz O, Thomas SM, Quan SF, Aronsky AJ. Quality measures for the care of adult patients with obstructive sleep apnea. J Clin Sleep Med. 2015;11:357-83.

4. Shawon MSR, Perret JL, Senaratna CV, Lodge C, Hamilton GS, Dharmage SC. Current evidence on prevalence and clinical outcomes of co-morbid obstructive sleep apnea and chronic obstructive pulmonary disease: a systematic review. Sleep Med Rev. 2017;32:58-68.

5. Marklund M, Verbraecken J, Randerath W. Non-CPAP therapies in obstructive sleep apnoea: mandibular advancement device therapy. Eur Respir J. 2012;39(5):1241-7.

6. Mehta A, Qian J, Petocz P, Darendeliler MA, Cistulli PA. A randomized, controlled study of a mandibular advancement splint for obstructive sleep apnea. Am J Respir Crit Care Med. 2001;163(6):1457-61.

7. Sutherland K, Takaya H, Qian J, Petocz P, Ng AT, Cistulli PA. Oral appliance treatment response and polysomnographic phenotypes of obstructive sleep apnea. J Clin Sleep Med. 2015;11(8):861-8.

8. Pitsis AJ, Darendeliler MA, Gotsopoulos H, Petocz P, Cistulli PA. Effect of vertical dimension on efficacy of oral appliance therapy in obstructive sleep apnea. Am J Respir Crit Care Med. 2002;166(6):860-4.

9. Marklund M. Predictors of long-term orthodontic side effects from mandibular advancement devices in patients with snoring and obstructive sleep apnea. Am J Orthod Dentofac Orthop. 2006;129(2):214-21.

10. Cistulli PA, Gotsopoulos H, Marklund M, Lowe AA. Treatment of snoring and obstructive sleep apnea with mandibular repositioning appliances. Sleep Med Rev. 2004;8(6):443-57.

11. Gotsopoulos H, Kelly JJ, Cistulli PA. Oral appliance therapy reduces blood pressure in obstructive sleep apnea: a randomized, controlled trial. Sleep. 2004;27(5):934-41.

12. George PT. Selecting sleep-disordered-breathing appliances. Biomechanical considerations J Am Dent Assoc. 2001;132:339-47.

13. Fransson AM, Tegelberg $\AA$, Johansson A, Wenneberg B. Influence on the masticatory system in treatment of obstructive sleep apnea and snoring with a mandibular protruding device: a 2-year follow-up. Am J Orthod Dentofac Orthop. 2004;126(6):687-93.

14. Long J, Ogawa T, Ito T, Matsuda M, Li W, Yu H, Sasaki K. Effect of bite openings and mandibular protrusion on genioglossus muscle activity in healthy adults with oral appliance. Odontology 2017;1-6 https://doi.org/10. 1007/s10266-017-0299-0. [Epub ahead of print].
15. Tuncer BB, Ozo ul B, Akkaya S. Differences in opening and protrusive mandibular movements between class I and II malocclusions in healthy adolescents. Korean J Orthod. 2011;41(2):127-37.

16. Kato J, Isono S, Tanaka A, Watanabe T, Araki D, Tanzawa H, Nishino T. Dosedependent effects of mandibular advancement on pharyngeal mechanics and nocturnal oxygenation in patients with sleep-disordered breathing. Chest. 2000;117(4):1065-72.

17. Piskin B, Karakoc O, Genc H, Akay S, Sipahi C, Erdem M, Karaman B, Gorgulu S, Yetkin S, Ayyildiz S. Effects of varying mandibular protrusion and degrees of vertical opening on upper airway dimensions in apneic dentate subjects. J Orofac Orthop. 2015;76(1):51-65.

18. Hammond RJ, Gotsopoulos H, Shen G, Petocz P, Cistulli PA, Darendeliler MA. A follow-up study of dental and skeletal changes associated with mandibular advancement splint use in obstructive sleep apnea. Am J Orthod Dentofac Orthop. 2007;132:806-14.

19. Vroegop AV, Vanderveken OM, Van de Heyning PH, Braem MJ. Effects of vertical opening on pharyngeal dimensions in patients with obstructive sleep apnoea. Sleep Med. 2012;13(3):314-6.

20. Svechtarov $V$, Hristova M, Nencheva-Svechtarova S, Tonche T. Mandibular range of motion and its relation to temporomandibular disorders. Scripta Scientifica Medicinae Dentalis. 2015;1(1):21-6.

21. Fransson AM, Tegelberg $\AA$, Svenson BA, Wenneberg B, Isacsson G. Validation of measurements of mandibular protrusion in the treatment of obstructive sleep apnoea and snoring with a mandibular protruding device. Eur J Orthod. 2003;25(4):377-83.

22. Takaesu Y, Tsuiki S, Kobayashi M, Komada Y, Nakayama H, Inoue Y. Mandibular advancement device as a comparable treatment to nasal continuous positive airway pressure for positional obstructive sleep apnea. J Clin Sleep Med. 2016;12(8):1113-9.

23. Posselt U. Studies in the mobility of the human mandible. Acta Odont Scandinav. 1952;10(Suppl10):19-160.

24. Ahn SJ, Tsou L, Sanchez A, Fels S, Kwon H. Analyzing center of rotation during opening and closing movements of the mandible using computer simulations. J Biomechanics. 2015;48:666-71.

25. Bonjardim LR, Gavião MBD, Pereira LJ, Castelo PM. Mandibular movements in children with and without signs and symptoms of temporomandibular disorders. J Appl Oral Sci. 2004;12(1):39-44.

26. Nielsen IL, Marcel T, Chun D, Miller AJ. Patterns of mandibular movements in subjects with craniomandibular disorders. J Prosthet Dent. 1990;63(2): 202-17.

27. Posselt U. Range of movement of the mandible. J Am Dent Assoc. 1958; 56(1):10-3.

28. Ingervall B. Variation of the range of movement of the mandible in relation to facial morphology in young adults. Scand J Dent Res. 1971;79(2):133-40.

29. Agerberg G. Maximal mandibular movements in young men and women. Sven Tandlak Tidskr. 1974;67(2):81-100.

30. Kang JH, Chung SC, Fricton JR. Normal movements of mandible at the mandibular incisor. J Prosthet Dentistry. 1991;66(5):687-92.

31. Dijkstra PU, Hof AL, Stegenga B, de Bont LG. Influence of mandibular length on mouth opening. Oral Rehabil. 1999;26(2):117-22.

32. Rose E, Staats R, Virchow C, Jonas IE. A comparative study of two mandibular advancement appliances for the treatment of obstructive sleep apnoea. Eur J Orthod. 2002;24(2):191-8.

33. Okawara Y, Tsuiki S, Hiyama S, Hashimoto K, Ono T, Ohyama K. Oral appliance titration and nasal resistance in nonapneic subjects. Am J Orthod Dentofac Orthop. 2004;126:620-2.

34. Ahrens A, McGrath C, Hägg U. A systematic review of the efficacy of oral appliance design in the management of obstructive sleep apnoea. Eur J Orthod. 2011;33(3):318-24.

35. Blanco J, Zamarrón C, Pazos MT, Lamela C, Quintanilla DS. Prospective evaluation of an oral appliance in the treatment of obstructive sleep apnea syndrome. Sleep Breath. 2005;9(1):20-5.

36. Petri N, Svanholt P, Solow B, Wildschiødtz G, Winkel P. Mandibular advancement appliance for obstructive sleep apnoea: results of a randomised placebo controlled trial using parallel group design. J Sleep Res. 2008;17(2):221-9.

37. Vanderveken OM, Devolder A, Marklund M, Boudewyns AN, Braem MJ, Okkerse W, Verbraecken JA, Franklin KA, De Backer WA, Van de Heyning PH. Comparison of a custom-made and a thermoplastic oral appliance for the treatment of mild sleep apnea. Am J Respir Crit Care Med. 2008;178(2):197202. 
38. Bloch KE, Iseli A, Zhang JN, Xie X, Kaplan V, Stoeckli PW, Russi EW. A randomized, controlled crossover trial of two oral appliances for sleep apnea treatment. Am J Respir Crit Care Med. 2000;162:246-51.

39. Gotsopoulos H, Chen C, Qian J, Cistulli PA. Oral appliance therapy improves symptoms in obstructive sleep apnea: a randomized, controlled trial. Am J Respir Crit Care Med. 2002;166(5):743-8.

40. Johnston CD, Gleadhill IC, Cinnamond MJ, Gabbey J, Burden DJ. Mandibular advancement appliances and obstructive sleep apnoea: a randomized clinical trial. Eur J Orthod. 2002;24(3):251-62.

41. Tegelberg Å, Walker-Engström ML, Vestling O, Wilhelmsson B. Two different degrees of mandibular advancement with a dental appliance in treatment of patients with mild to moderate obstructive sleep apnea. Acta Odontol Scand. 2003;61(6):356-62

42. Walker-Engström ML, Ringqvist I, Vestling O, Wilhelmsson B, Tegelberg Å. A prospective randomized study comparing two different degrees of mandibular advancement with a dental appliance in treatment of severe obstructive sleep apnea. Sleep Breath. 2003;7(3):119-30

43. Gauthier L, Laberge L, Beaudry M, Laforte M, Rompré PH, Lavigne GJ. Efficacy of two mandibular advancement appliances in the management of snoring and mild-moderate sleep apnea: a cross-over randomized study. Sleep Med. 2009;10(3):329-36.

44. Hans MG, Nelson S, Luks VG, Baek SJ. Comparison of two dental devices for treatment of obstructive sleep apnea syndrome (OSAS). Am J Orthod Dentofac Orthop. 1997:111(5):562-70.

45. Kuna ST, Giarraputo PC, Stanton DC, Levin LM, Frantz D. Evaluation of an oral mandibular advancement titration appliance. Oral Surg, Oral Med, Oral Pathol, Oral Radiol, Endod. 2006;101(5):593-603.

46. Gagnadoux F, Fleury B, Vielle B, Pételle B, Meslier N, N'Guyen XL, Trzepizur $W$, Racineux JL. Titrated mandibular advancement versus positive airway pressure for sleep apnoea. Eur Respir J. 34(4):914-20.

47. Lamont J, Baldwin DR, Hay KD, Veale AG. Effect of two types of mandibular advancement splints on snoring and obstructive sleep apnoea. Eur J Orthod. 1998:20:293-7.

48. Lowe AA. Oral appliances for sleep breathing disorders. In: Kryger MH, Roth T, Dement WC, editors. Principles and practice of sleep medicine. 3rd ed. Philadelphia: Saunders; 2000. p. 929-39.

49. de Almeida FR, Bittencourt LR, de Almeida Cl, Tsuiki S, Lowe AA, Tufik S. Effects of mandibular posture on obstructive sleep apnea severity and the temporomandibular joint in patients fitted with an oral appliance. Sleep. 2002;25(5):505-11.

50. L'Estrange PR, Battagel JM, Harkness B, Spratley MH, Nolan PJ, Jorgensen GI. A method of studying adaptive changes of the oropharynx to variation in mandibular position in patients with obstructive sleep apnoea. J Oral Rehabil. 1996:23:699-711.

51. Aarab G, Lobbezoo F, Hamburger HL, Naeije M. Effects of an oral appliance with different mandibular protrusion positions at a constant vertical dimension on obstructive sleep apnea. Clin Oral Investig. 2010;14(3):339-45.

Ready to submit your research? Choose BMC and benefit from:

- fast, convenient online submission

- thorough peer review by experienced researchers in your field

- rapid publication on acceptance

- support for research data, including large and complex data types

- gold Open Access which fosters wider collaboration and increased citations

- maximum visibility for your research: over $100 \mathrm{M}$ website views per year

At $\mathrm{BMC}$, research is always in progress.

Learn more biomedcentral.com/submissions 